\title{
Novel Ferritic Stainless Steel with Advanced Mechanical Properties and Significant Magnetic Responses Processed by Selective Laser Melting
}

\author{
Shang Feng ${ }^{1,2}$, Chen Xiaoqiu ${ }^{2}$, Zhang Peng ${ }^{2}$, Ji Zuchun ${ }^{3}$, Ming Fei ${ }^{1}$, Ren Shubin ${ }^{1, *}$ and Qu Xuanhui ${ }^{1}$ \\ ${ }^{1}$ Institute for Advanced Materials and Technology, University of Science and Technology Beijing, Beijing 100083, P. R. China \\ ${ }^{2}$ Marine Resources Development Institute of Jiangsu, Huaihai Institute of Technology, Lianyungang, Jiangsu Province 222005, P. R. China \\ ${ }^{3}$ Mingyang Technology (Suzhou) Co., Ltd., Suzhou, Jiangsu Province 222005, P. R. China
}

Novel ferritic stainless steel with advanced mechanical properties and significant magnetic responses was prepared by a selective laser melting (SLM) process from UNS S32707 hyper-duplex stainless steel (HDSS) powder prepared by a plasma rotating electrode process (PREP). The microstructure, mechanical properties, and soft magnetic properties of the sintered state were studied. The results show that ferritic stainless steel with a relative density of $98.2 \%$ (with the theoretical density of $7.8 \mathrm{~g} / \mathrm{cm}^{3}$ ) can be prepared by SLM with a laser energy density of $87.96 \mathrm{~J} / \mathrm{mm}^{3}$ and $67^{\circ}$ of rotation of the upper and lower layers. The rapid cooling after sintering inhibits the formation of austenite, and the ferrite content reaches $98.5 \%$. Sintered parts prepared by SLM have excellent mechanical properties. The measured tensile strength, yield strength, and the microhardness were $1493 \mathrm{MPa}, 1391 \mathrm{MPa}$, and $528.7 \mathrm{HV}$, respectively. The nitrogen content decreased by 33\% during SLM. Nitrides precipitated at ferrite grain boundaries lower the ductility and toughness of sintered parts prepared by SLM. The measured elongation, the reduction of area, and the impact absorbing energy were $13.2 \%, 24.1 \%$, and $18 \mathrm{~J}$, respectively. The high ferrite content causes sintered parts prepared by SLM to have excellent soft magnetic properties. The specific saturation magnetization and the coercivity were $106 \mathrm{Am}^{2} / \mathrm{kg}^{2}$ and $1.79 \mathrm{mT}$, respectively. This provided a new approach for the near net shaping of structural and functional integrated soft magnetic materials with both strength and corrosion resistance. [doi:10.2320/matertrans.M2018374]

(Received November 30, 2018; Accepted March 25, 2019; Published May 25, 2019)

Keywords: selective laser melting, ferritic stainless steel, microstructure, mechanical property, magnetic response

\section{Introduction}

Metal materials for oceanographic engineering are generally characterized by properties that include high corrosion resistance, strength, impact toughness, and fatigue resistance. ${ }^{1)}$ Specifically, UNS S32707 hyper-duplex stainless steel (HDSS) exhibits excellent mechanical properties and corrosion resistance, and it can meet the harsh service requirements of a deep-sea environment. The use of HDSS provides several advantages, such as thinner offshore engineering structures, weight reduction, a saving of raw materials, and cost reduction. This material is widely used in seawater heat exchangers, pipeline cables in offshore oilfields, sea water desalination, flue gas desulfurization, subsea Christmas trees, and other devices, and HDSS is considered to be an ideal material for use in deep-sea oil and gas exploitation equipment to replace nickel-based corrosionresistant alloys. ${ }^{2,3)}$ HDSS is easy to crack when prepared by a traditional hot rolling process, and the high nitrogen content of the steel leads to poor weldability. ${ }^{4-7)}$ Nearly completely densified duplex stainless steel products can be prepared by selective laser melting (SLM). A faster sintering cooling rate can avoid the precipitation of the $\sigma$ phase and other harmful phases. ${ }^{8}$ This can also be used to prepare duplex stainless steel products using near net shaping with complex shapes that are difficult to manufacture with casting and forging. SLM has higher requirements for the purity, morphology, and particle size distribution of powders. A powder prepared by nitrogen atomization has low batch stability with respect to the generation of a satellite powder and a hollow powder. Additionally, the oxygen content is high in this type of powder, and this is not beneficial for the enhanced

*Corresponding author, E-mail: sbren@ustb.edu.cn performance of powder-sintered pieces. Crucible pollution may increase the impurity content in powder and reduce powder purity, and thus the fine powder yield is low and the powder price is high. Crucible pollution can be avoided via the plasma rotating electrode process (PREP). Hence, the impurity content in powder is extremely low and this aids in generating stainless steel sphere powders with a high amount of nitrogen. This type of powder exhibits good mobility, high nitrogen content, low oxygen content, fine particle size, and good sphericity. Therefore, it satisfies the market demands for metal additive manufacturing.

In recent years, some scholars have studied the preparation of super-duplex stainless steel (SDSS) with SLM. Saeidi ${ }^{9)}$ studied the preparation of SAF 2507 SDSS with SLM, and that study found a high density and excellent mechanical properties. The relative density was $99.5 \%$, and the tensile strength, the yield strength, and the hardness were $1321 \mathrm{MPa}$, $1214 \mathrm{MPa}$, and $450 \mathrm{HV}$, respectively. Davidson ${ }^{10-12)}$ studied the preparation of UNS S32750 SDSS with SLM. The relationship between the laser energy density, the ferrite content, and magnetic properties was found. The porosity after sintering significantly affected the grain orientation and the grain growth. The anisotropy of the grain led to a higher specific saturation magnetization $\left(110.9 \mathrm{Am}^{2} / \mathrm{kg}\right)$ of the SLM specimens compared with the forgings. Hengsbach ${ }^{13)}$ studied the microstructure and the mechanical properties of UNS S31803 SDSS with SLM. It was found that the recrystallized microstructure prevailed after heat treatment due to the appearance of a large number of dislocations. Compared to the samples after heat treatment, the dislocation movement was hindered by the existence of a high dislocation density and nitride. A higher tensile strength and a lower elongation at the break were found. Although SLM technology has a certain basis for the preparation of SDSS, SLM of HDSS 
Table 1 Chemical composition of UNS S32707 HDSS powder (mass\%).

\begin{tabular}{cccccccccccc}
\hline $\mathrm{Cr}$ & $\mathrm{Ni}$ & $\mathrm{Mo}$ & $\mathrm{N}$ & $\mathrm{Si}$ & $\mathrm{Mn}$ & $\mathrm{Co}$ & $\mathrm{Cu}$ & $\mathrm{Al}$ & $\mathrm{C}$ & $\mathrm{O}$ & $\mathrm{Fe}$ \\
\hline 27.19 & 6.48 & 5.00 & 0.36 & 0.58 & 1.50 & 1.03 & 0.98 & 0.02 & 0.02 & 0.018 & Bal. \\
\hline
\end{tabular}

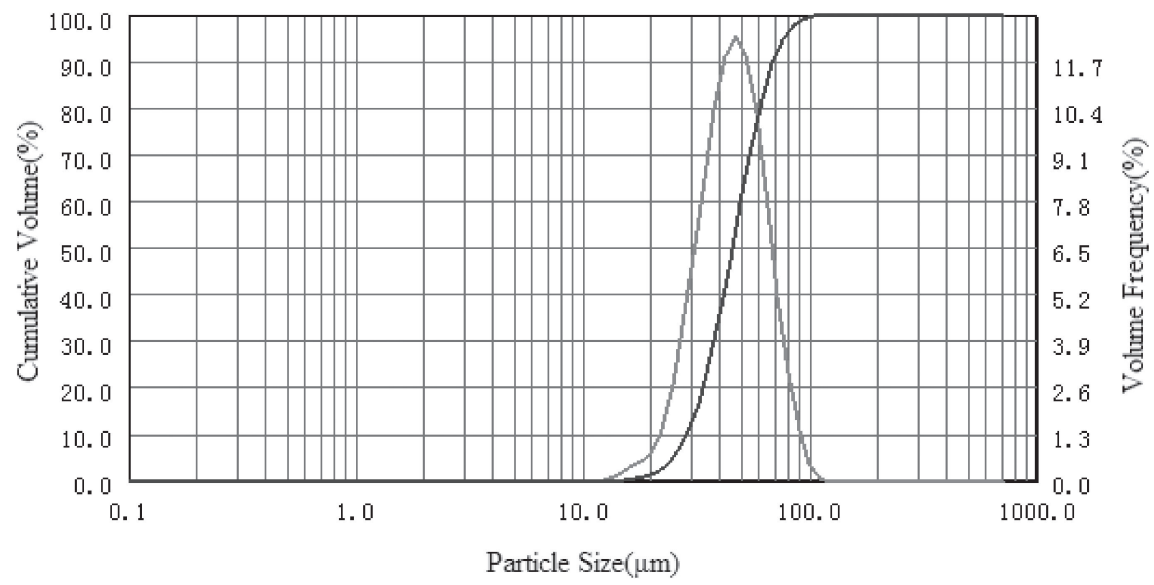

Fig. 1 Particle size distribution of the powder.

has rarely been reported. Changes in the nitrogen content, microstructure, mechanical properties, and soft magnetic properties during sintering have yet to be studied.

The mechanical properties and corrosion resistance of UNS S32707 HDSS are higher than those of UNS S32750 (SAF 2507) SDSS. ${ }^{14)}$ It has higher Cr, Mo, and N contents, and the pitting resistance equivalent number (PREN = mass $\% \mathrm{Cr}+3.3$ mass $\% \mathrm{Mo}+16$ mass $\% \mathrm{~N})$ can be as high as 49 . The critical pitting temperature $(\mathrm{CPT})$ is about $90^{\circ} \mathrm{C}$. This material can satisfy the extremely harsh service environment requirements of high temperature, high pressure, high chloride ion amounts, strong acidity, and so on. It can be used to replace nickel-based corrosion resistant alloys for deep-sea oil and gas exploitation equipment, thus greatly saving costs. ${ }^{2)}$ In this study, novel ferritic stainless steel with advanced mechanical properties and significant magnetic responses was prepared with the SLM process from UNS S32707 HDSS powder prepared by PREP. The microstructure, mechanical properties, and soft magnetic properties of the sintered state were studied.

\section{Experimental Procedure}

An electrode bar of UNS S32707 HDSS (Shenyang Zhongke Sannai New Materials Co., Ltd.) with the size of $\Phi 80 \times 700 \mathrm{~mm}$ was atomized into powder using PREP equipment (Sino-Euro Materials Technologies of Xi'an Co., Ltd.). In the PREP process, the electrode bar, which rotated at 28000-29000 rpm in an argon atmosphere at 0.05-0.1 MPa, was melted by an plasma arc at a constant DC current of 1400-1500 A. The chemical composition of the powder is shown in Table 1. Figures 1, 2, and 3 show the particle size distribution, the morphology, and the phase composition of the atomized powders. As shown in Fig. 1, it can be seen that the median diameter of the prepared metal powder was about $45 \mu \mathrm{m}$, and the particle size distribution range was narrow

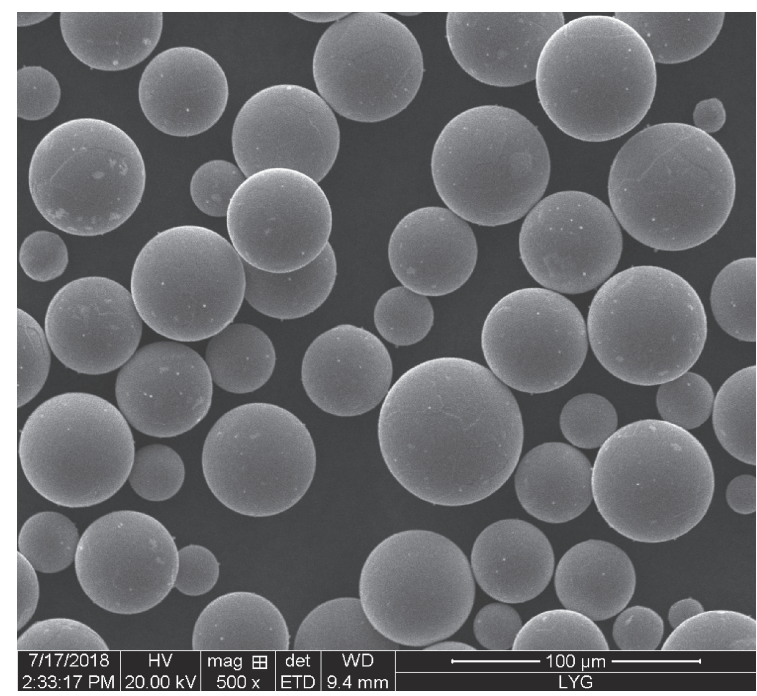

Fig. 2 The morphology of the powder.

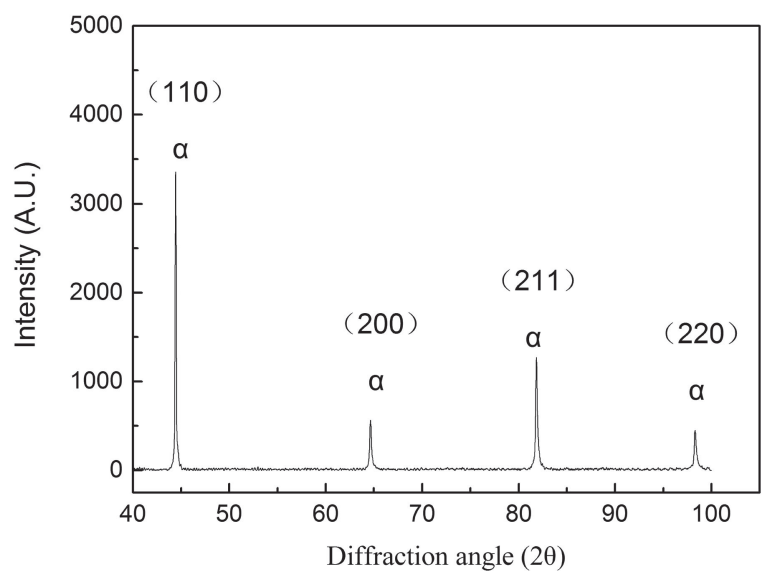

Fig. 3 XRD of the powder. 

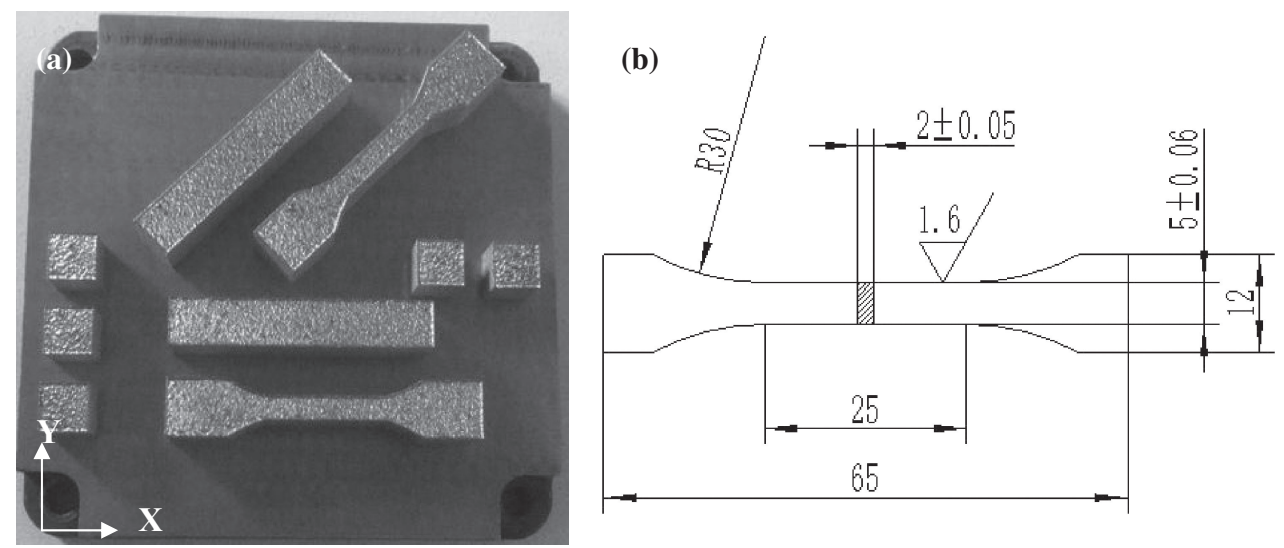

Fig. 4 The macroscopic appearance of the sintered specimens prepared by SLM (a) as well as tensile specimen size (b).

and suitable for SLM sintering. An scanning electron microscope (SEM) analysis of Fig. 2 shows that the powder was regularly spherical, and an X-ray diffractometer (XRD) of Fig. 3 shows that the phase composition of the powder was composed of a single phase, with no impurity phase or harmful phase.

The atomized powder was sintered using SLM equipment (FS121M, Hunan Farsoon High-Technology Co., Ltd.) in a nitrogen atmosphere, and the upper and lower layers were rotated $67^{\circ}$ to compensate for the height difference between the center and the edge caused by the laser scanning between adjacent layers and to reduce the internal porosity caused by the height difference. ${ }^{15}$ ) The sintering parameters included a laser power of $190 \mathrm{~W}$, a scanning speed of $800 \mathrm{~mm} / \mathrm{s}$, a powder layer thickness of $0.03 \mathrm{~mm}$, a hatch spacing of $0.09 \mathrm{~mm}$, and a laser energy density of $87.96 \mathrm{~J} / \mathrm{mm}^{3}$. The macroscopic appearance and the tensile specimen size of the sintered specimens prepared using SLM are shown in Fig. 4. Cube samples $10 \times 10 \times 10 \mathrm{~mm}$ in size were used for microstructure observation. Rectangular samples $55 \times 10 \times$ $10 \mathrm{~mm}$ in size were machined into $\mathrm{V}$-notches for the impact test. A circular ring sample with a $40 \mathrm{~mm}$ outer diameter, a $32 \mathrm{~mm}$ inner diameter, and a thickness of $5 \mathrm{~mm}$ was used for the soft magnetic property test, and a cube sample with a size of $2 \times 2 \times 2 \mathrm{~mm}$ was used for the vibration sample magnetometer to measure the specific saturation magnetization.

The microstructure of the prepared metal powder was observed by a Quanta FEG 450 SEM. An HKL Channel5 electron backscatter diffraction (EBSD) analysis system equipped in an FEI Quanta 650F field emission SEM was used to determine the proportion of each phase in the sample. The microstructure was observed by an FEI Tecnai G2 F20 transmission electron microscope (TEM). An FEI Superenergy dispersive spectrometer (EDS) system equipped in an FEI Titan Themis spherical aberration electron microscope was used for a high-resolution energy surface scan test. A Smart Lab X-ray diffractometer of Rigaku (Japan) $\left(\mathrm{Cu} \mathrm{K} \mathrm{K}_{\alpha}\right.$, $\lambda=0.15406 \mathrm{~nm}$ ) was used to analyze the phase constituents of the powder. The mechanical properties were measured by a WDW-10E microcomputer controlled electronic universal testing machine, and the nitrogen content in the powder and sintered parts was measured by a LECO ONH 836 Oxygen Nitrogen Hydrogen Analyzer. The density of the sintered parts was measured by a DH-300X electronic gravimeter, the microhardness of the samples was measured by an HV-30 hardness tester, and the hysteresis loop of the sample was measured by an MATS-2010SD soft magnetic DC measuring instrument. The specific saturation magnetization of the specimen was measured by an XM2017-TZ0784 vibrating sample magnetometer.

\section{Results and Discussion}

\subsection{Microstructure}

Figure 5 shows the EBSD diagram (X-Y plane) of the UNS S32707 specimen prepared using SLM. From the inverse pole figure in Fig. 5(a) and the pole figures in Fig. 5(b), it can be seen that the SLM samples have no obvious texture orientation. This is related to the relative rotation of the upper and lower layers at $67^{\circ}$ during sintering, which weakens the grain anisotropy tendency. From the phase distribution figure of Fig. 5(c), it can be seen that the SLM sample consisted of $\alpha, \gamma$, and $\mathrm{Cr}_{2} \mathrm{~N}$ components, and the content percentages were $98.5 \%, 0.2 \%$, and $0.3 \%$, respectively. The grain size distribution of ferrite is shown in Fig. 5(d), and the average $3.68 \mu \mathrm{m}$ grain size of the ferrite can be determined by analyzing Fig. 5(d). The smaller grain size is helpful for improving the mechanical properties with fine grain strengthening. Figure 6 is the TEM diagram of the UNS S32707 sample prepared by SLM. A large number of dislocations can be observed in the interior of the ferrite grain in Fig. 6(a). The white granular second phase precipitated at the ferrite grain boundary as shown in Fig. 6(b). EDS mapping shows that the $\mathrm{Cr}$-rich and $\mathrm{N}$-rich regions were found at the ferrite grain boundary, indicating that $\mathrm{Cr}_{2} \mathrm{~N}$ precipitated at the ferrite grain boundary. A small number of spherical $\mathrm{Al}_{2} \mathrm{O}_{3}$ inclusions were also found in the ferrite crystals, as shown in Fig. 6(c).

The thermal gradient, the solidification speed, and the scanning direction are the key parameters affecting the microstructure. ${ }^{16,17)}$ SLM has the characteristics of high temperature heating and rapid cooling, which is similar to the process of PREP. An XRD analysis of the powder in Fig. 3 showed that the atomized powder had changed from a biphasic structure to a single phase ferrite structure after plasma arc heating and gas cooling. A dynamic point heat source and a related transient heat field made the melt powder of single phase ferritic stainless steel completely solidify into 


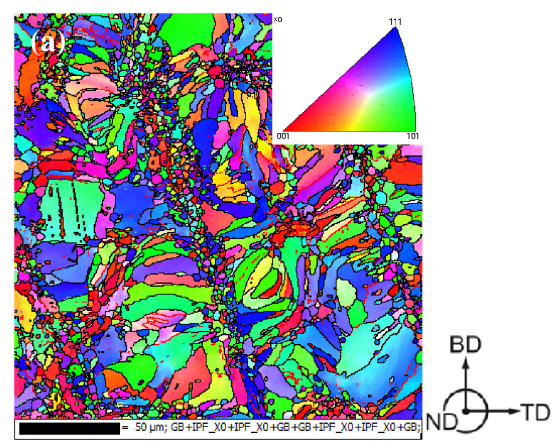

(b)
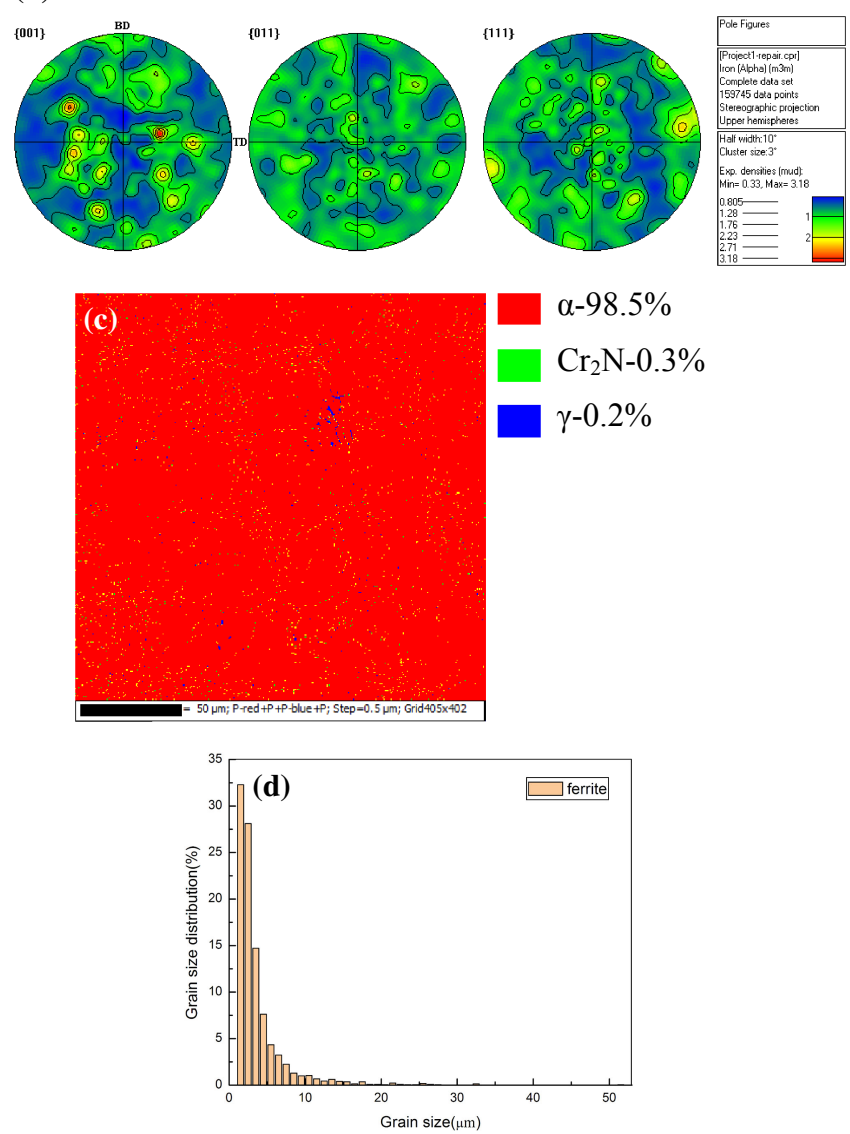

Fig. 5 The EBSD diagram (X-Y plane) of the UNS S32707 specimen prepared by SLM (a) inverse pole figure; (b) pole figures; (c) phase distribution figure; and (d) grain size distribution of ferrite.

high temperature ferrite according to the dynamic order of $\mathrm{L} \rightarrow \delta+\mathrm{L} \rightarrow \delta$. Its cooling rate was about $10^{4}-10^{6} \mathrm{~K} / \mathrm{s}$. The high cooling rate inhibited the formation of austenite, and the rapid heat dissipation led to a high stress and induced a high dislocation density. Davidson ${ }^{12)}$ and Hengsbach ${ }^{13)}$ also obtained high ferrite content and high density dislocations during the SLM process for preparing UNS S32750 and UNS S31803 SDSS. Saeidi ${ }^{9)}$ prepared SAF 2507 SDSS using SLM and formed a unique mosaic structure using the vertical scanning of the upper and lower layers. A large number of dislocation loops were found in the grain interior and the recrystallization boundary.

Figure 6(c) shows that $\mathrm{Cr}_{2} \mathrm{~N}$ precipitated at the ferrite grain boundaries. This was because the residual heat in the upper layer of the powder did not escape during the continuous laser scanning and the covering of the powder layer, which was equivalent to the isothermal heat treatment $\left(700-900^{\circ} \mathrm{C}\right)$ of the next layer of the powder. The supersaturated nitrogen in ferrite is easy to enrich at grain boundaries. This intergranular nitride is also called isothermal nitride. The existence of this isothermal nitride has also been confirmed by the study of Saeidi ${ }^{9)}$ and Hengsbach. ${ }^{13}$ ) Another precipitation form of $\mathrm{Cr}_{2} \mathrm{~N}$ took place during the fast cooling from the high solution annealing temperatures, presumably because of the supersaturation of the ferritic phase with nitrogen, and $\mathrm{Cr}_{2} \mathrm{~N}$ particles precipitated mostly intragranularly, with a crystallographic relationship of $\langle 0001\rangle_{\mathrm{Cr} 2 \mathrm{~N}} \|\langle 011\rangle_{\delta}{ }^{18,19)}$ The nitrogen content in the casting bar and the powder were $0.39 \%$ and $0.36 \%$ respectively. This shows that the appropriate PREP process will not significantly reduce the nitrogen content of the casting bar after atomization. The nitrogen content in the sintered parts was only $0.24 \%$, and the nitrogen content decreased by $33 \%$ during SLM sintering, which affected the solution annealing temperature and led to the imbalance of the ferrite and austenite ratio and the decrease of the pitting resistance equivalent. Whether the quantitative relationship between the nitrogen atmosphere pressure, the laser energy density, and nitrogen content can be established remains a question for future study.

\subsection{Mechanical properties}

The oxygen content in the casting bar and the powder were $0.006 \%$ and $0.018 \%$ respectively. The particle size distribution range of the PREP powder was $15-53 \mu \mathrm{m}$, the larger specific surface area of the fine powder led to the increase of the oxygen content. The oxygen content of the PREP powder is still lower than that of the vacuum gas atomized powder, which is beneficial to the increase of the sintered density. The mechanical properties of UNS S32707 HDSS prepared by different processes are shown in Table 2. Sintered parts prepared using SLM have excellent mechanical properties under the combined action of dislocation strengthening, precipitation strengthening, and fine grain strengthening due to a large number of dislocations in the ferrite grains and nano-nitrides precipitated at grain boundaries, and an average grain size of $3.68 \mu \mathrm{m}$ for the ferrite. The measured tensile strength, the yield strength, and the microhardness were $1493 \mathrm{MPa}, 1391 \mathrm{MPa}$, and $528.7 \mathrm{HV}$, respectively. The strength reached the grade of ultra-high strength steel, and the strength and hardness were much higher than that of the casting bar for PREP. The nitrides precipitated at ferrite grain boundaries lowered the ductility and toughness of the sintered parts prepared using SLM. The measured elongation, the reduction of area, and the impact absorbing energy were $13.2 \%, 24.1 \%$, and $18 \mathrm{~J}$, respectively. Figure 7 shows the tensile (a) and impact (b) fracture morphologies of the SLM specimens. A small amount of dimples and tearing edges was found on the tensile fracture surface, which was characterized by a mixed fracture of toughness and brittleness. There was obvious cleavage fracture morphology in the impact fracture surface, which was a brittle fracture.

\subsection{Soft magnetic properties}

Figure 8 shows the magnetic hysteresis loop of the specimen in the $\mathrm{X}-\mathrm{Y}$ plane perpendicular to the sintering 

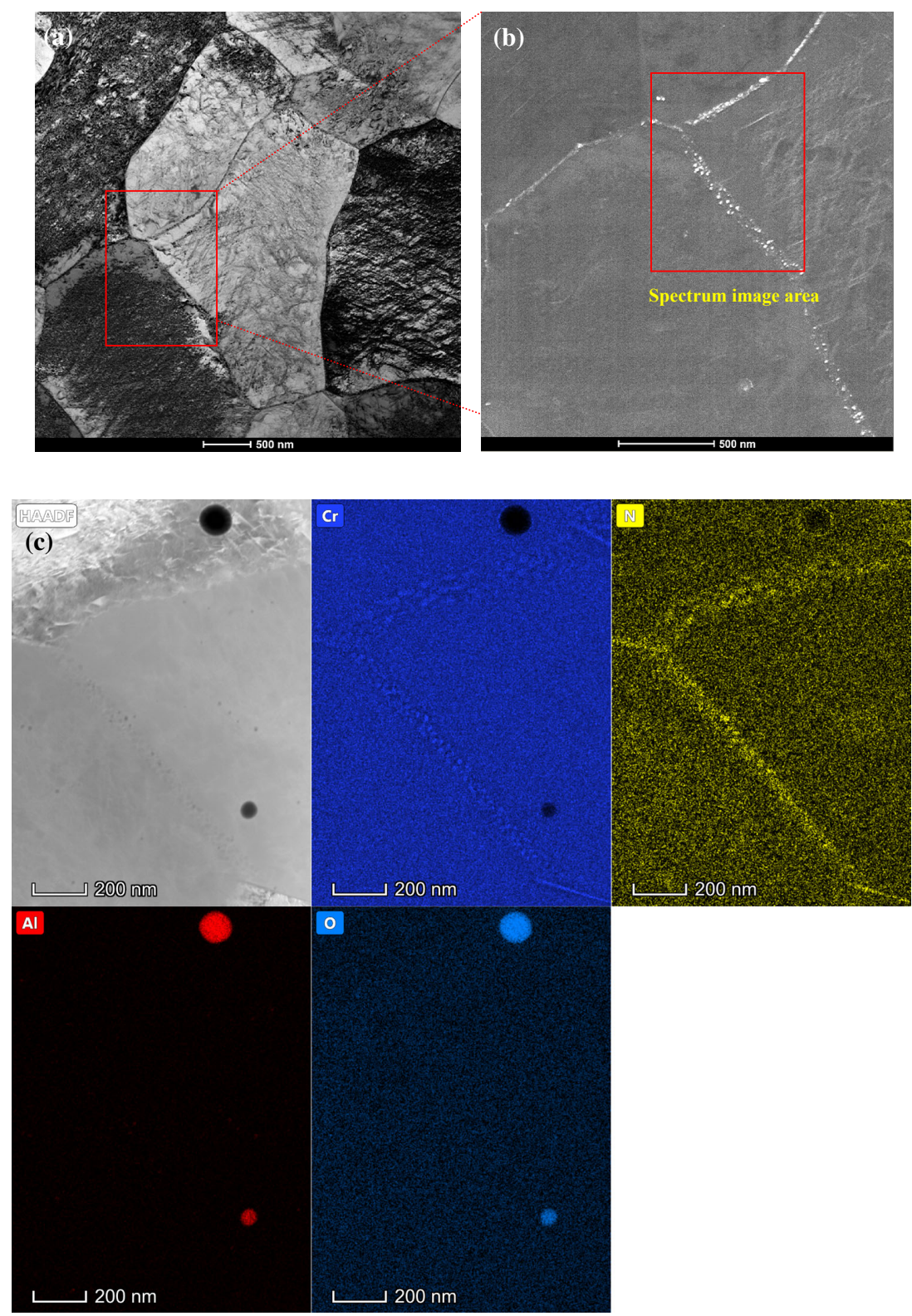

Fig. 6 TEM morphology of the UNS S32707 sample prepared by SLM (a) TEM bright field image; (b) TEM dark field image; and (c) STEM-EDS mapping image.

Table 2 The mechanical properties of UNS S32707 HDSS prepared by different processes.

\begin{tabular}{ccccccc}
\hline Type & $\begin{array}{c}\text { Tensile } \\
\text { strength } \\
(\mathrm{MPa})\end{array}$ & $\begin{array}{c}\text { Yield } \\
\text { strength } \\
(\mathrm{MPa})\end{array}$ & $\begin{array}{c}\text { Elongation } \\
(\%)\end{array}$ & $\begin{array}{c}\text { reduction } \\
\text { of area } \\
(\%)\end{array}$ & $\begin{array}{c}\text { Microhardness } \\
(\mathrm{HV})\end{array}$ & $\begin{array}{c}\text { Impact } \\
\text { absorbing } \\
\text { energy } \\
(\mathrm{J})\end{array}$ \\
\hline $\begin{array}{c}\text { This work } \\
\text { Casting bar }\end{array}$ & 1493 & 1391 & 13.2 & 24.1 & 528.7 & 18 \\
$\begin{array}{c}\text { UNS S32707 } \\
\text { for PREP }\end{array}$ & 814 & 678 & 2 & 2 & 302 & 3.5 \\
\hline
\end{tabular}

direction prepared by SLM. Table 3 shows the soft magnetic properties of different kinds of duplex stainless steel. The obvious $\langle 001\rangle$ crystal orientation was not found using the laser scanning strategy in this experiment. The high specific saturation magnetization was mainly caused by an ultra-high ferrite content of $98.5 \%$. The lower coercivity was due to the average grain size of $3.68 \mu \mathrm{m}$ for the ferrite. As shown in Table 3, the specific saturation magnetization and coercivity of the SLM samples from UNS S32707 powder were similar to the properties of the SLM samples from SAF 2507 powder. The SLM samples had a higher specific saturation magnetization compared to forgings. 


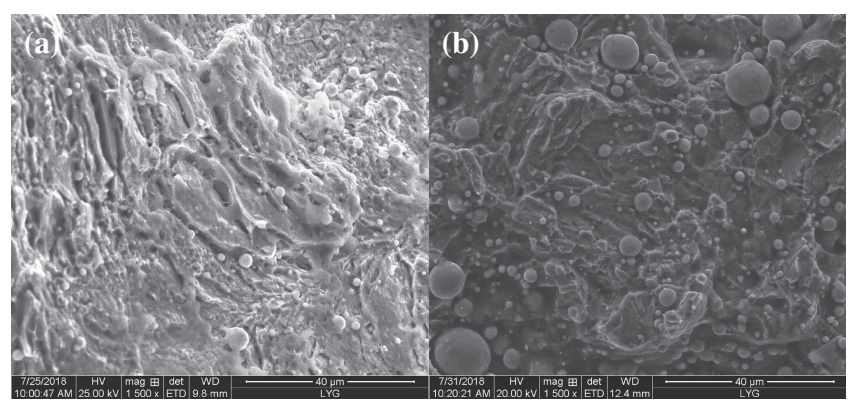

Fig. 7 The tensile (a) and impact (b) fracture morphologies of the SLM specimens.

\section{Conclusions}

(1) Novel ferritic stainless steel with advanced mechanical properties, significant magnetic responses, and a relative density of $98.2 \%$ can be prepared using SLM from a UNS S32707 HDSS powder with a laser energy density of $87.96 \mathrm{~J} / \mathrm{mm}^{3}$ and $67^{\circ}$ of rotation of the upper and lower powder layers. This material exhibited random grain orientation and weak anisotropy due to the special scanning strategy.

(2) The rapid cooling after sintering inhibited the formation of austenite, and the ferrite content reached $98.5 \%$. Sintered parts prepared using SLM had excellent mechanical properties due to a large number of dislocations in the ferrite grains, the nano-nitrides precipitated at grain boundaries, and a $3.68 \mu \mathrm{m}$ average grain size of ferrite. The measured tensile strength, the yield strength, and the microhardness were $1493 \mathrm{MPa}$, $1391 \mathrm{MPa}$, and $528.7 \mathrm{HV}$, respectively. The nitrogen content decreased by $33 \%$ during SLM. Nitrides that precipitated at the ferrite grain boundaries lowered the ductility and toughness of sintered parts prepared using SLM. The measured elongation, the reduction of area, and the impact absorbing energy were $13.2 \%, 24.1 \%$, and $18 \mathrm{~J}$, respectively.

(3) The high specific saturation magnetization of the SLM samples was mainly caused by an ultra-high ferrite content of $98.5 \%$ compared to forgings. The lower coercivity was due to the average $3.68 \mu \mathrm{m}$ grain size of the ferrite. The specific saturation magnetization and the coercivity were $106 \mathrm{Am}^{2} / \mathrm{kg}$ and $1.79 \mathrm{mT}$, respectively.

\section{Acknowledgment}

This study was financially supported by the National Science and Technology Support Program of the Ministry of Science and Technology of China (No. 2015BAE03B00), National Natural Science Foundation of China (No. 51874038, 51604239), Fundamental Research Funds for the Central Universities (FRF-AT-18-014), the Jiangsu 333 High Level Talent Project (No. BRA2016293), Jiangsu UniversityIndustry Cooperation Project (BY2018210), the Natural Science Foundation of Huaihai Institute of Technology (Z2017001), Lianyungang 521 Project (ZKK201805) and Lianyungang Haiyan Project (2018-QD-013). We thank Dr.
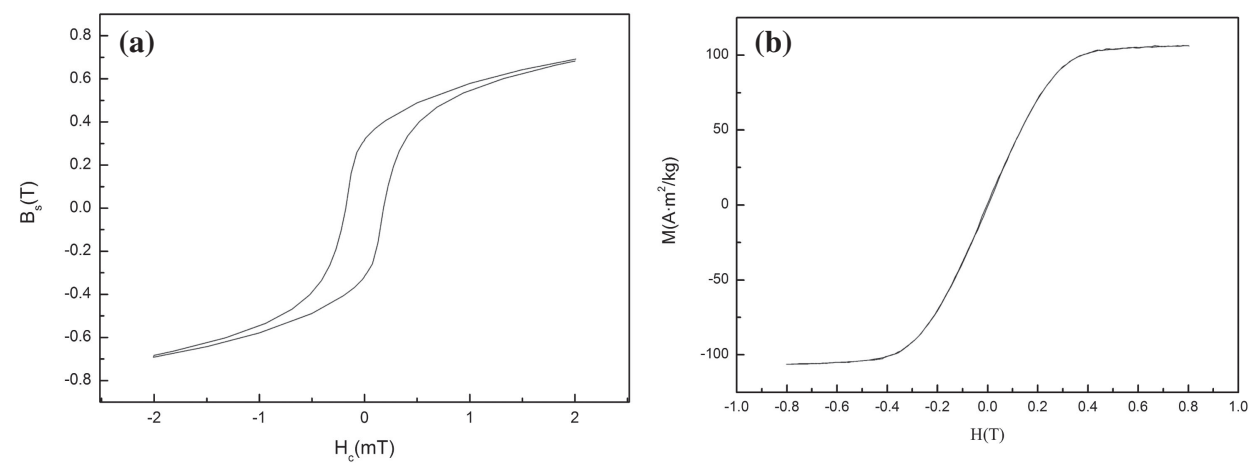

Fig. 8 The magnetic hysteresis loop of the specimen in the X-Y plane perpendicular to the sintering direction prepared by SLM (a) Coercivity ( $\mathrm{X}$ axis) measured by a soft magnetic direct current measuring instrument; (b) Specific saturation magnetization (Y axis) measured by a vibrating magnetometer.

Table 3 The soft magnetic properties of different kinds of duplex stainless steel.

\begin{tabular}{ccccc}
\hline Material & Process & $\begin{array}{c}\text { Specific saturation } \\
\text { magnetization } \\
\left(\mathrm{Am}^{2} / \mathrm{kg}\right)\end{array}$ & $\begin{array}{c}\text { Coercivity } \\
(\mathrm{mT})\end{array}$ & Researcher \\
\hline $\begin{array}{c}\text { UNS } \\
\text { S32707 }\end{array}$ & SLM & 106 & 1.79 & $\begin{array}{c}\text { This study } \\
\text { SAF 2507 }\end{array}$ \\
& SLM & 110.9 & 1.81 & $\begin{array}{c}\text { K.P. Davidson et al. } \\
{[10]}\end{array}$ \\
SAF 2507 & Wrought & 45.1 & 0.92 & $\begin{array}{c}\text { K.P. Davidson et al. } \\
{[10]}\end{array}$ \\
\hline
\end{tabular}


Jiasheng Dong and research fellow Langhong Lou from Shenyang Zhongke Sannai New Materials Co., Ltd. for his help in alloy melting. We thank Dr. Shujin Liang from SinoEuro Materials Technologies of Xi' an Co., Ltd. for his help in PREP. We thank Dr. Xiaoming Zhang and Dr. Xuehao Zheng from ZKKF (Beijing) Science and Technology Co., Ltd. for TEM and EBSD observations.

\section{REFERENCES}

1) G. Chail and P. Kangas: Procedia Struct. Integr. 2 (2016) 1755-1762.

2) H. Feng, X.Y. Zhou, H. Liu and Z.G. Song: J. Iron Steel Res. 27 (2015) 1-5 (in Chinese)

3) Z.G. Song, H. Feng and S.M. Hu: J. Iron Steel Res. Int. 24 (2017) 121130

4) L. Karlsson: Weld World 56 (2012) 65-76.

5) H.J. Kim, S.H. Jeon, S.T. Kim, I.S. Lee, Y.S. Park, K.T. Kim and Y.S. Kim: Corros. Sci. 87 (2014) 60-70.

6) J. Pilhagen, H. Sieurin and R. Sandström: Mater. Sci. Eng. A 606 (2014) 40-45.

7) H.J. Kim, S.H. Jeon, S.T. Kim and Y.S. Park: Corros. Sci. 91 (2015)
$140-150$.

8) F. Martín, C. García, Y. Blanco and M.L. Rodriguez-Mendez: Mater. Sci. Eng. A 642 (2015) 360-365.

9) K. Saeidi, L. Kevetkova, F. Lofaj and Z. Shen: Mater. Sci. Eng. A 665 (2016) 59-65.

10) K.P. Davidson and S. Singamneni: JOM 69 (2017) 569-574.

11) K.P. Davidson and S. Singamneni: Mater. Manuf. Process. 31 (2016) 1543-1555.

12) K.P. Davidson and S. Singamneni: Rapid Prototyping J. 23 (2017) 1146-1163.

13) F. Hengsbach, P. Koppa, K. Duschik, M.J. Holzweissig, M. Burns, J. Nellesen, W. Tillmann, T. Tröster, K.P. Hoyer and M. Schaper: Mater. Des. 133 (2017) 136-142.

14) S.H. Jeon, I.J. Park, H.J. Kim, S.T. Kim, Y.K. Lee and Y.S. Park: Mater. Trans. 55 (2014) 971-977.

15) Y.J. Xie, H.C. Yang, X.B. Wang, C.J. Kuang and W. Han: Powder Metall. Ind. 28 (2018) 18-24 (in Chinese).

16) X.Q. Wang and K. Chou: JOM 69 (2017) 402-408.

17) L. Thijs, K. Kempen, J.P. Kruth and J.V. Humbeeck: Acta Mater. 61 (2013) 1809-1819.

18) O. Smuk: Ph.D. Thesis, Royal Institute of Technology, (2004).

19) N. Pettersson, R.F.A. Pettersson and S. Wessman: Metall. Mater. Trans. A 46 (2015) 1062-1072. 